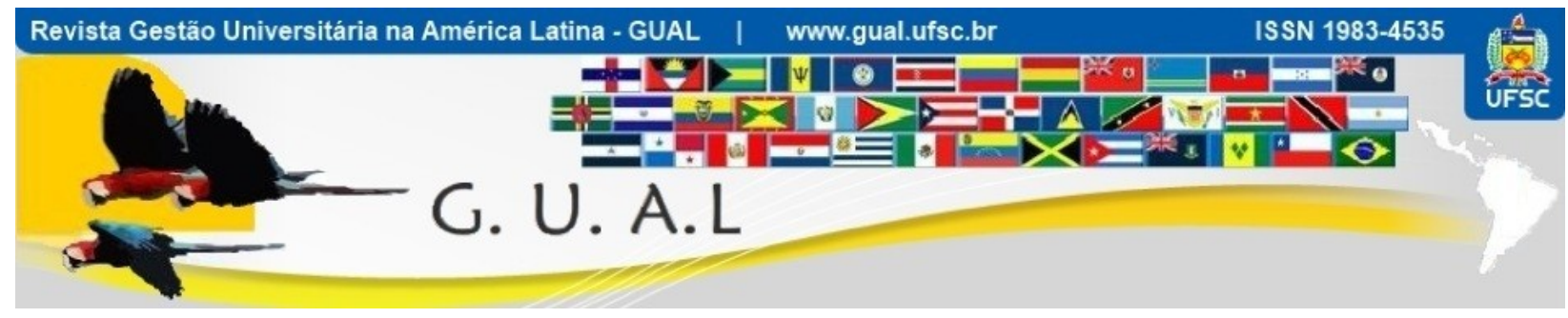

DOI: http://dx.doi.org/10.5007/1983-4535.2015v8n2p113

\title{
O MARKETING SOCIAL EM PROJETOS DE RESPONSABILIDADE SOCIAL UNIVERSITÁRIA
}

\section{THE SOCIAL MARKETING IN SOCIAL RESPONSIBILITY PROJECTS IN THE UNIVERSITY}

Marcus Vinicius de Oliveira Brasil, Doutor

Universidade Federal do Cariri - UFCA mvobrasil@gmail.com

Fabiana Pinto de Almeida Bizarria, Doutoranda Universidade de Fortaleza - Unifor bianapsq@hotmail.com

Mônica Mota Tassigny, Doutora Universidade de Fortaleza - Unifor monica.tass@gmail.com

Randal Martins Pompeu, Doutor Universidade de Fortaleza - Unifor randal@unifor.br

Francisco Correia de Oliveira, PhD Universidade Estadual do Ceará - UECE fcdeol@gmail.com

Recebido em 18/junho/2014

Aprovado em 13/fevereiro/2015

Sistema de Avaliação: Double Blind Review

Esta obra está sob uma Licença Creative Commons Atribuição-Uso. 


\title{
RESUMO
}

Esta pesquisa busca responder a seguinte inquietação: como se dá a promoção do Marketing Social através das ações de Responsabilidade Social de uma Fundação Educacional? O objetivo geral desse artigo é estudar como as ações de Responsabilidade Social em projetos sociais de uma Fundação Educacional estão vinculadas ao Marketing Social. Parte-se do princípio de que as ações de Responsabilidade Social de uma Fundação Educacional estão relacionadas ao Marketing Social. Esta pesquisa é um estudo de caso único incorporado, em que são estudados oito projetos sociais. $\mathrm{O}$ critério de seleção das entrevistas foi intencional. A técnica utilizada foi a Análise de Conteúdo, também foi feita uma pesquisa bibliográfica e documental. Os resultados demonstram que esses projetos sociais fomentam a inclusão social e a promoção do bem comum na luta pelos direitos humanos, por intermédio de valores, como solidariedade, ética socioambiental e altruísmo, além de envolverem a família e um atendimento humanizado. São projetos de Responsabilidade Social pautados pela prática do Marketing Social na Universidade.

Palavras-chave: Marketing Social. Responsabilidade Social. Fundação Educacional. Projetos Sociais.

\begin{abstract}
This research seeks to answer the following question: how is the promotion of social marketing through the actions of social responsibility of an Educational Foundation? The general aim of this paper is to study how the actions of social responsibility in social projects of an Educational Foundation are linked to social marketing. It is established the assumption that the actions of social responsibility of an Educational Foundation are related to social marketing. This research is a single case study, which are studied eight social projects. The selection criterion of the interviews was intentional. The technique used was content analysis and was also performed a bibliographic and documentary research. The results demonstrate that these projects promote social inclusion and common good in the fight for human rights, through values such as solidarity, environmental ethics and altruism, and involve family and humanized care. Social responsibility projects are guided by the practice of social marketing in the university.
\end{abstract}

Keywords: Social Marketing. Social Responsibility. Educational Foundation. Social Projects. 


\section{INTRODUÇÃO}

A Teoria da Responsabilidade Social comporta temas ligados ao marketing social, que é uma espécie de atitude institucional nem sempre voltada para o mercado que objetiva apresentar soluções para questões de cunho social, dentro dos seguintes temas: higiene, alimentação, saúde, trabalho, educação, moradia e transporte (VAZ, 1995). Carroll (1999) assinala que as organizações que fazem uso da Responsabilidade Social para além de obter lucros e obedecer à lei, elas também buscam ser éticas e passar uma imagem de empresa cidadã.

O Marketing Social possui metas e objetivos específicos, que devem ser desenvolvidos e planejados pelo gestor, empresário ou empreendedor por meio de sua equipe. Para Kotler e Roberto (1992), o Marketing Social promove a mudança social através de projetos institucionais que levam uma prática social a uma determinada localidade ou grupo que assimilam esse desafio.

O mercado é essencialmente dinâmico, as inovações são necessárias, os produtos e serviços que hoje são inovadores podem ficar obsoletos em um curto espaço de tempo. É necessária nas organizações uma atenção especial na direção de novos mercados e oportunidades de negócios. Como ensinam Kotler e Zaltman (1971), o Marketing Social direcionam programas ou projetos específicos visando atingir objetivos sociais em um determinando grupo.

O Marketing Social cria um comportamento pró-social, que facilita vencer as barreiras que se contrapõem para as pessoas não se engajarem em atividades específicas de segmentos sociais, como ações de Responsabilidade Social (McKENZIE-MOHR, 2000). Na perspectiva de envolver um maior número de pessoas nos programas ofertados pelo Marketing Social, a inovação social quebra estas barreiras de entrada, que não são as mesmas encontradas ao nível do marketing voltado para o mercado, mas que podem se valer das estratégias de mercado, tais como promoções e vendas.

A inovação social demanda uma atividade de criação de valor social, cujos objetivos econômicos são meios e os sociais são fins, podendo ocorrer nas ou entre organizações não lucrativas, lucrativas e públicas (AUSTIN; STEVENSON; WEI-SKILLERN, 2006).

A pergunta de partida desse trabalho é a seguinte: como se dá a promoção do Marketing Social através das ações de Responsabilidade Social de uma Fundação Educacional? O objetivo geral desse trabalho é estudar como as ações de Responsabilidade 
Social em projetos sociais de uma Fundação Educacional estão vinculadas ao Marketing Social. Parte-se do pressuposto central de que as ações de Responsabilidade Social de uma Fundação Educacional estão relacionadas ao Marketing Social.

\section{MARKETING SOCIAL}

Será, no entanto, que é possível diferenciar o marketing social do marketing comercial? Os estudos do Centro Britânico de Marketing Social esclarecem que o marketing social é a aplicação sistemática de conceitos e técnicas de marketing comercial para atingir comportamentos específicos em prol do bem social (FRENCH; BLAIR-STEVENS, 2006). Na realidade, na concepção do marketing social, não se está reinventado tudo desde do início, mas utilizando o conhecimento prévio do que foi aprendido durante decádas sobre marketing para aplicar de maneira adaptada ao social.

Essa é a lógica de aproveitar o poder do marketing comercial e as forças de mercado de maneira inovadora, de forma a criar sociedades e economias mais sustentáveis, evitando uma ruptura entre novos estilos de vida adotados, mais socioambientalmente responsáveis e as estruturas de mercado (PEATTIE; PEATTIE, 2009). Isso inclui a conscientização pelo consumo responsável, bem como a redução do consumo, e estilos de vida mais simples e sustentáveis.

O acesso ao consumo de bens industrializados, no entanto, já não é uma realidade para todos os habitantes da Terra, quanto mais à aquisição de produtos sustentáveis, que em geral agregam custos ambientais de produção. No entendimento do ex-ministro da educação do Brasil, Buarque (1993, p. 3), pode-se dizer que "o consumo como o sonho de liberdade, do crescimento da indústria com a tendência à igualdade, percebe-se que o consumo não pode ser para todos; o rumo seguido pela indústria é incompatível com a igualdade, o consumo se choca com a liberdade".

De acordo com os ensinamentos de Jansson e Marell (2010, p. 359, tradução nossa) "o comportamento de redução do impacto ambiental negativo (por exemplo, conservação de energia e reciclagem) tem recebido muito mais atenção do que o comportamento do consumidor de comprar produtos que são comercializados como sendo ambientalmente responsáveis". Na realidade, mesmo se houver um exacerbado consumo por produtos verdes, não se contribui para minorar os efeitos das atividades, principalmente industriais, que suportam estes produtos ou serviços. 
A escolha de um comportamento pró-social na conservação socioambiental é de sumo interesse da sociedade, principalmente no longo prazo, ou seja, para as gerações futuras. Os custos associados a esse tipo de atitude, porém, tais como dinheiro, esforço e certos incovenientes podem tentar as pessoas a continuarem fazendo escolhas egoístas de curto prazo, ou mais voltadas a uma racionalidade econômica (CORNELISSEN et al., 2007). Este é um problema a ser levantado nas discussões da sustentabilidade das decisões a serem tomadas em empresas comerciais.

O esforço do Marketing Social deve ser no sentido de provocar nas lideranças empresariais uma conscientização de que não é somente dever do Estado compartilhar o ônus dos problemas sociais, nem tão somente do Terceiro Setor, mas também é uma tarefa que diz respeito às empresas lucrativas.

\begin{abstract}
A comunicação de massa atua de forma paradoxal: assim como exerce um papel de mobilizadora de esforços para constituir uma base de entendimento entre tantas leituras diferentes também é responsável pela omissão e difusão discriminada de mensagens ambientais meramente corporativas. (MATTOZO; CAMARGO, 2005, p. 121).
\end{abstract}

Segundo Vaz (1995, p. 281), “Os problemas sociais podem ser classificados em quatro esferas de atuação humanitária, que definem a sua natureza: Qualidade de Vida, Capacitação Pessoal, Convivência Social e Sobrevivência”. Quanto à capacitação profissional, estamos falando de gestão de pessoas e não de recursos humanos, pois as pessoas devem preceder os recursos nas organizações.

Há outra modalidade de marketing, o chamado Marketing de Causas Sociais (MCS), que "pode ser definido como uma ferramenta estratégica de marketing e de posicionamento que associa uma empresa ou marca a uma questão ou causa social relevante, em benefício mútuo" (PRINGLE; THOMPSON, 2000, p. 3). É inegável que uma campanha de MCS bem articulada não dê um retorno publicitário para a empresa. Não se pode negar que existe na sociedade uma lógica de mercado essencialmente capitalista, porém propiciar aos trabalhadores melhores condições de trabalho e vida, por via da responsabilidade social, e fazer o marketing em cima disto, são maneiras de atrair as atenções das empresas.

É difícil perceber, a priori, quais são as verdadeiras intenções das empresas com relação a isso, pois é necessário vislumbrar sua filosofia empresarial e seus valores éticos. E não só isso, mas constatar se eles estão impregnados na cultura empresarial. Para Levitt (1990, p. 63), “Como as palavras são baratas e as ações são caras, pode ser adequado indicar o que esta espécie de pensamento envolve e para onde conduz". 
Pois existe, com certeza, um ônus maior a ser pago por estas empresas que se dizem socialmente responsáveis e na verdade não o são. O marketing, neste caso, funciona como um contrassenso e seus efeitos podem ser imaginados: descrédito e desconfiança. Conforme Camargo, Capobianco e Oliveira (2004, p. 39), “existem poucos resultados e ações socioambientais em relação ao marketing propagado pelas empresas".

Não é o lucro em si, entretanto, o vilão neste caso, mas sim a falta de investimentos em obras sociais, que possibilitem melhor convivência social e sobrevivência das comunidades. O Marketing Social é uma realidade comum ao mundo das empresas não lucrativas e das que objetivam lucros. As mídias podem influenciar, mas devem respeitar a liberdade individual de escolha:

A liberdade individual é essencialmente um produto social, e não uma relação de mão dupla entre: (I) arranjos sociais para expandir as liberdades individuais e (2) o uso das liberdades individuais não só para melhorar a vida dos respectivos, mas também para fazer os arranjos sociais mais adequados e eficazes. (SEN, 1999a, p. 31 , tradução nossa).

É necessário perceber que os consumidores, além de procurarem preço e qualidade, nessa nova fase do capitalismo, denominada de desenvolvimento sustentável, passaram a se preocupar com os efeitos que as atividades empresariais dos setores industriais, de serviços e do comércio trazem ao meio ambiente (SCHALTEGGER; WAGNER, 2011). Enquanto for possível reciclar e reutilizar, as empresas propagarão estas ideias, visto que, além da redução de custos de materiais, elas irão ao encontro das necessidades das futuras gerações de terem um meio ambiente adequado para dar continuidade à vida humana.

É importante, todavia, ter cuidado com ações de empresas que realmente não têm nenhum compromisso com a sociedade. Em vez disso, tentam tirar proveito na construção da imagem da marca e da organização. A mudança vem da visão do líder, criando valores éticos em sua filosofia empresarial, devendo exercer sua liderança junto à equipe para que todos busquem colocar em prática estes valores na missão da empresa, e por fim para que eles norteiem o planejamento estratégico. De acordo com Bursztyn e Bursztyn (2012, p. 31), "Declarar-se favorável à sustentabilidade não quer dizer necessariamente agir em conformidade com o discurso!".

As relações humanas estão sendo revisitadas. Os estudos socioeconômicos, ao apontarem soluções sustentáveis ao Planeta, antes de serem aplicados, devem ser fortemente criticados de modo a garantir o desenvolvimento sustentável. As organizações, ao veicularem uma mensagem de Marketing Social na mídia, o consumidor deve abrir mão das imagens 
primeiras, das impressões que um fenômeno nos deixa a princípio, e caminhar numa abstração crescente, distanciando-se do explícito, no intuito de verificar se ali existe realmente uma ação Responsabilidade Social (LEVITT, 1990).

Boa parte do que é pura manipulação ideológica da mídia e dos meios midiáticos procura justamente atingir as questões do inconsciente individual ou coletivo. O código que decifra a vida tem guarida nas incompreensões e subjetivações e más interpretações do inconsciente. "A ecosofia mental, por sua vez, [...] será levada a procurar antídotos para a uniformização midiática e telemática, o conformismo das modas, as manipulações da opinião pela publicidade, pelas sondagens etc." (GUATTARI, 1990, p. 16).

São vistos grandes apelos promocionais das diversas mídias, principalmente da televisiva, tentando capturar e manipular as pessoas, criando desejos que apelam até para o consumo irresponsável e não consciente. A ecologia mental está atrelada ao inconsciente das pessoas, é lá que estão os processos mentais obscuros ao entendimento humano ao nível do consciente; a mídia já descobriu isto.

Somente a opinião das pessoas acerca de uma ação social organizacional, mas desacompanhada da ética da Responsabilidade Social, foge no conceito do Marketing Social, visto que muitos empresários utilizam o buzz marketing, ou seja, o marketing boca a boca no intuito de conquistar clientes (COLOMBO et al., 2005).

É preciso tomar cuidado com organizações que disseminam até falsos conceitos acerca de si mesmas, simplesmente objetivando lucros. Este tipo de procedimento é denominado "greenwashing" ou "lavagem verde".

O ambientalismo, por seu elevado consenso e por sua legitimação simbólica, está presente nas normas sociais da sociedade moderna. Dessa maneira, o apoio discursivo e a prática de ações 'pró-ambiente' são fontes geradoras desse capital simbólico. (FONSECA; BURSZTYN, 2007, p. 172).

As certificações e os selos ambientais que deveriam evitar a "lavagem verde" convertem capital simbólico em lucro econômico para as organizações, ou seja, quando existe uma discrepância entre o discurso e a prática. Já que o produto ecologicamente correto vende uma boa imagem da organização, pode ser o caso de se explorar isso de forma irresponsável (FONSECA; BURSZTYN, 2007).

Em razão do Marketing Social, os consumidores estão cada vez mais interessados em produtos e serviços que atendam ao quesito da responsabilidade social. Mathew (2009) explicou que, se a empresa é percebida pelo seu público como antiética, terá sua reputação 
manchada, por isso mesmo, as organizações devem mostrar respeito pelas pessoas e pelo Planeta, e, só então, podem pensar em lucrar com sua boa reputação. De acordo com Ashley et al. (2002, p. 32), “A educação do consumidor para o consumo responsável deve considerar dimensões ambientais, econômicas e sociais".

A Responsabilidade Social é um dever eminentemente da humanidade, pois cada pessoa, empresa, instituição e nação devem ser conscientizadas na preservação dos recursos naturais. A sociedade, ao se preparar para o consumo responsável, está pensando nas gerações futuras, que, de acordo com Schrader e Thogersen (2011, p. 3, tradução nossa) asseveram:

\footnotetext{
Na realidade, o consumo responsável tem atraído os estudiosos de muitas disciplinas no mundo inteiro. Publicações recentes neste tópico têm focado principalmente no significado do consumo privado para o desenvolvimento sustentável e no esclarecimento da questão da sustentabilidade como um novo conceito (exemplo destes estudiosos, Hansen e Schrader, 1997; Heiskanen e Pantazar, 1997; Spaargaren, 2003; Spangenberg e Lorek, 2002).
}

O consumidor passou a apostar mais nas empresas socialmente responsáveis por vários motivos: credibilidade, sensação de estar ajudando a sociedade, preocupações ambientais, filosofia de vida etc. Não se pode negar que os empreendedores, que se preocupam com o social, estão lucrando com isso. "Em face das mutantes e crescentes expectativas de clientes, de fornecedores, do pessoal interno e dos gestores, a empresa do futuro tem de agir de forma responsável em seus relacionamentos internos e externos" (TACHIZAWA, 2008, p. 53).

Quando existe o reinvestimento no social, as empresas são mais bem aceitas, e as pessoas fazem o marketing boca a boca, ou buzz marketing; pois esta última modalidade de marketing está constituída sobre uma rede de relações que se conectam de formas diversas. Conforme Colombo et al. (2005, p. 146), "buzz marketing é a abordagem de marketing fundamentada nos rumores e comentários nas ligações, assim como redes sociais por onde essa comunicação trafega".

Especificamente no caso do Marketing Social, porém, quando as empresas entenderem a necessidade de exercer a responsabilidade de seus atos econômicos, sociais, ambientais e tecnológicos, verão seus processos como conscientes da preservação da vida. O consumidor mais exigente, tomando consciência disso, somente consumirá produtos destas empresas e naturalmente elas lucrarão mais. Não será preciso fingir do socialmente responsável para lucrar mais. "A ecologia social deverá trabalhar na reconstrução das relações humanas em todos os níveis, do socius" (GUATTARI, 1990, p. 33). 
O Marketing Social deve ser aplicado na sociedade, pois leva a uma conscientização das questões socioambientais, promovendo uma reflexão anterior, levando ao senso comum uma circulação desta nova visão, promovendo a vida. Isso não diz respeito somente ao governo, terceiro setor ou às empresas, mas a toda a humanidade. "A mediação promovida pela mídia desempenha um papel significativo na sociedade contemporânea ao constituir e difundir representações sociais que contribuem para formar condutas, orientar as comunicações sociais" (MATTOZO; CAMARGO, 2005, p. 108).

Existem diferenças, porém, entre o Marketing Social e o sustentável? O marketing sustentável é definido como a construção e a manutenção de relacionamentos com os clientes na ambiência social e ambiental, criando valor ao incrementar melhores serviços, de acordo com as necessidades e desejos deles por via de soluções sustentáveis (BELZ; SCHMIDTRIEDIGER, 2010).

De acordo com Nidumolu, Prahalad e Rangaswami (2009, p. 9, tradução nossa) "Para desenhar produtos sustentáveis, as companhias precisam entender os anseios do consumidor e examinar cuidadosamente o ciclo de vida dos produtos. Elas devem aprender a combinar habilidades de marketing com suas competências..." Faz-se necessário entender que cada vez mais as pessoas estão sendo conscientizadas nas escolas, universidades e pela mídia do consumo sustentável.

Concluímos que, levando em consideração o senso comum, e a perspectiva da ciência, o Marketing Socioambiental é promotor de um mundo mais sustentável, mas ainda existem empresários, organizações e governos que tentam tirar proveito, enganando as pessoas na sociedade ao se esforçar para apenas usar o marketing como mero instrumento promocional, objetivando aumentar os lucros empresariais ou melhorar a imagem da instituição, o que é denominado de lavagem verde.

\section{METODOLOGIA}

O método é o caminho escolhido pelo pesquisador para responder a sua inquietação científica acerca de um tema ou assunto. Esta pesquisa é um estudo de caso único incorporado (YIN, 2005) com as seguintes subunidades de análise da Fundação Educacional: Escola de Aplicação (EA), Centro de Formação (CF), Projeto Jovem Voluntário (PJV), Educação e Saúde (PESDA), Núcleo Médico (NMEDI), Clínica de Odontologia (CO), Escritório Jurídico (EJ) e o Projeto Cidadania Atuante (PCATU). 
O método da Análise de Conteúdo (AC) envolve organização da análise, codificação, categorização, inferência e tratamento informático (BARDIN, 1977, p. 42). Aqui também foi feita uma pesquisa documental, além da revisão bibliográfica. Trata-se de pesquisa qualitativa em que foi usada a técnica de AC na análise dos dados das entrevistas abertas da pesquisa de campo com os alunos, funcionários, usuários, professores dos projetos sociais da Fundação Educacional.

O critério de seleção das quinze entrevistas foi intencional e não seguiu nenhum procedimento estatístico. As entrevistas foram aplicadas no período de setembro a outubro de 2013. A pesquisa ocorreu dentro do campus da Universidade e no seu entorno. Na AC temática, registram-se as palavras e se as relacionam a temas ou menções expressas, criando categorias específicas (SILVERMAN, 2009).

\section{ENQUADRAMENTO CONTEXTUAL}

O Ceará é um dos 27 estados brasileiros, sendo o sexto mais populoso, de acordo com os dados do IBGE (2008), com 8.452.381 habitantes, e é também o décimo sétimo estado em área, com quase $149.000 \mathrm{~km}^{2}$, sendo que o Ceará ocupa o sétimo lugar em relação aos demais estados, com a maior proporção de pessoas em condição de miséria (IPECE, 2011).

A capital, Fortaleza, tem mais de 2,5 milhões de habitantes, sendo a quinta capital em termos de tamanho no Brasil, sendo que sua área metropolitana ultrapassa a casa dos 3,4 milhões de habitantes (IPECE, 2011). A cidade de Fortaleza é a capital administrativa e política do Estado do Ceará, destino turístico no Brasil. É uma cidade bem urbanizada, tendo na composição da chamada Região Metropolitana de Fortaleza (RMF) 15 municípios: Fortaleza, Aquiraz, Caucaia, Cascavel, Eusébio, Guaiúba, Horizonte, Itaitinga, Maracanaú, Maranguape, Pacajus, Pacatuba, Pindoretama, São Gonçalo do Amarante e Chorozinho (CEARÁ, 2011).

A Fundação Educacional estudada tem em seu entorno a comunidade do Dendê, "sendo fácil constatar a presença de insegurança, falta de saneamento básico, cultura da violência doméstica, uso de drogas, violência e constrangimentos impostos a crianças e adolescentes" (ANDRADE; COSTA, 2013, p. 277). O quesito social refere-se aos membros da sociedade e tudo que possa afetá-la, questões como: pobreza, educação, saúde pública, trabalho etc (WERBACH, 2009).

Apesar desta situação ser negligenciada pelas políticas estaduais e municipais, a Fundação Educacional tenta melhorar seu entorno "por meio de projetos que resgatem a 
autoestima, o conhecimento pessoal dos direitos humanos" (ANDRADE; COSTA, 2013, p. 277), mas, quanto à parte econômica ainda são necessárias ações que satisfaçam as necessidades demandadas, tais como água, segurança alimentar, moradia etc.

No quesito saúde pública, no NMEDI, “durante o ano de 2009 foram atendidos 25.552 pacientes e realizados 373.320 procedimentos. Em 2010, pode-se constar o atendimento de 10.729 pacientes e a realização de 194.713 procedimentos." No período de julho de 2012 a julho de 2013, o número total de atendimentos foi de 297.132, envolvendo 184 profissionais, sendo 142 profissionais de saúde e 42 da área administrativa; tendo 516 estágios disciplinares nas áreas de Terapia Ocupacional, Fonoaudiologia, Psicologia, Fisioterapia, Laboratório de Análises Clínicas e Farmácia; e 27 estágios voluntários, totalizando 543 estagiários (POMPEU; MARQUES, 2013, p. 261).

Cada CO tem 100 consultórios que atendem diariamente mais de 300 pessoas, entre crianças, jovens e adultos, nas áreas de Dentística (restaurações), Endodontia (tratamento de canal), Periodontia (gengiva), Cirurgia, Prótese (fixa, removível e total), Ortodontia, Odontopediatria e Radiologia. (BRASIL, 2014).

O EJ proporciona assistência jurídica sem ônus para a comunidade, oferecendo serviços de consultas, encaminhamento de processos e orientações de natureza legal. É uma oportunidade para os alunos de colocarem em prática os conhecimentos adquiridos na sala de aula, mediante estágio curricular com orientação dos professores do curso de Direito. São feitos anualmente cerca de 2.800 atendimentos de assessoria jurídica no EJ em diversos níveis de necessidade, nas áreas criminal e cível. "A universidade oferece assistência gratuita a pessoas carentes que buscam a solução de conflitos de natureza familiar, consumerista, penal, tributária, entre outras" (POMPEU; MARQUES, 2013, p. 262).

Criado em 2001, o PCATU, constitui uma forma inovadora de integrar os corpos docente e discente da Universidade no desenvolvimento voluntário de atividades voltadas para a conscientização de direitos nas comunidades, além da intervenção direta na execução de projetos especiais e do desenvolvimento de políticas públicas para governos e instituições não governamentais. Alunos e professores voluntários do curso de Direito desenvolvem, nos 31 programas em curso, palestras, reuniões, apostilas, folders e cartilhas, com o objetivo de fortalecer a cidadania, levando o conhecimento jurídico até a comunidade.

O PCATU envolve distintas áreas do Direito, tais como: direitos humanos; direito do idoso, direitos e deveres da criança e do adolescente, da mulher e da família; Direito do Trabalho, Direito Civil, Direito Penal, Direito do Consumidor, Direito Previdenciário e 
Tributário- além de temas como terceiro setor, Direito e Psicologia, Ensino Jurídico, Ética Profissional e Responsabilidade Social, Poder Político e Cidadania, Acesso à Justiça e a Mudança Social, Empreendedorismo etc (BRASIL, 2014).

A Escola de Aplicação foi inaugurada em 1982 e cumpre o papel de inclusão social com educação formal de crianças de baixa renda. Desde o início, a escolinha sempre foi gratuita. No projeto da Escola de Aplicação, a criança recebe fardamento, alimentação, material escolar e didático gratuitos. A criança recebe apoio psicopedagógico, tendo em seu currículo Educação Física e Língua Estrangeira, e ainda pode fazer várias atividades complementares, dentre as quais: informática, artes plásticas e dança (ANDRADE, COSTA, 2013; CRUZ, 1998).

As comunidades inovadoras desenvolvem um ambiente inovador por meio de uma estrutura facilitadora, pelo fato, de a comunidade unida focar em seu objetivo, com flexibilidade suficiente para acatar novas ideias de seus membros, transformando em atividades práticas (WEST, 2009). Nos dias atuais, a escolinha continua cumprindo sua missão de educar. "Anualmente, a escola proporciona educação gratuita a cerca de 660 crianças do infantil III, da educação infantil até a $3^{\mathrm{a}}$ série do ensino fundamental I, residentes nas comunidades carentes, vizinhas ao campus" (ANDRADE, COSTA, 2013, p. 279).

O CF teve o início das atividades em 2002 e oferta várias capacitações, dentre elas: empreendedorismo, qualificação para a Copa do Mundo, o curso de garçom e cumin (auxiliar de garçom), arrumadeira de hotel etc, tendo dado atenção especial a públicos diferenciados como os portadores de necessidades especiais e com sustentabilidade no custeio de suas atividades. Os dados apontam que "durante o ano de 2009, 1.885 pessoas receberam formação profissionalizante nas áreas tecnológicas, administrativas e da saúde e desde a sua criação já foram treinados 10.032 alunos" (POMPEU; MARQUES, 2013, p. 263).

No Brasil, o problema da fome é reflexo de um sociedade global cheia de desigualdades sociais. Segundo Sen (1999a; tradução nossa), "Muitíssimas pessoas em todo o mundo sofrem de vários tipos de falta de liberdade. Bolsões de fome continuam ocorrer em determinadas regiões, negando a milhões a liberdade básica de sobreviver”. O Ceará é um dos estados da República Federativa do Brasil que mais sofre com os efeitos da seca e consequentemente do desemprego (CEARÁ, 2011).

O PJV teve seu início em 2001 e "tem como propósito a formação de jovens para exercerem sua cidadania, levando alunos [...] para instituições, hospitais, organizando festas 
com pacientes em um período de seis meses...”. Pelo projeto, até 2012, já foram atendidas mais de 8.000 pessoas (POMPEU; MARQUES, 2013, p. 261-262).

Ao final do período de participação, o jovem voluntário estudante de graduação da Universidade recebe um certificado de participação de acordo com a Lei do Voluntariado. O PJV contava no semestre de 2012.1 com cerca de 650 alunos, que foram selecionados e capacitados, para fazerem um trabalho lúdico e voluntário com crianças e idosos hospitalizados dentro de unidades conveniadas (BRASIL, 2014).

A criatividade é fomentada nos projetos sociais da Fundação Educacional, desenvolvidos em grupos específicos, criando uma espécie de comunidade universitária inovadora, que, na concepção de West (2009), deve incluir: diversidade, interdependência, participação dos membros dos grupos envolvidos, geração e seleção de ideias e suporte à inovação.

Tendo iniciado em 2002, o Projeto Educação e Saúde (PESDA) objetiva alfabetizar crianças, jovens, adultos e idosos enquanto realiza hemodiálise. O projeto tem parceria do Instituto do Rim e já foram atendidas mais de 1.380 pessoas, com cerca de 20 alunos envolvidos no projeto (BRASIL, 2014).

As universidades desempenham papel fundamental, não só na educação e pesquisa, mas também nas políticas de desenvolvimento extensionista, na troca de informações e inserção comunitária na perspectiva de criar um futuro justo e sustentável (SHRIBERG, 2002).

\section{RESULTADOS E DISCUSSÃO}

Os entrevistados sobre o projeto social da Escola de Aplicação falaram da importância social desse projeto que atende crianças carentes da comunidade de entorno, assim como filhos de funcionários da Universidade nas séries iniciais da vida escolar. O envolvimento da família com a EA aparece como questão-chave, principalmente por causa do convívio social que as crianças enfrentam, e preparar essas crianças para a cidadania, com orientações pedagógicas preventivas contra o mundo das drogas, é uma atitude importante para estabelecer uma sociedade sustentável, uma vez que as drogas destroem vidas, profissões e famílias. "Se a recuperação social de pessoas viciadas em drogas envolve tratamentos de desintoxicação, acompanhamento psicológico e outras providências onerosas, a prevenção contra o uso de drogas apresenta-se como uma ação de Marketing Social” (VAZ, 1995, p. 284). 
A conscientização ambiental aparece como outra prática evidente na Escolinha, uma vez que isso é trabalhado nos conteúdos escolares. Essa conscientização envolveu todo o campus da Universidade, como disse a coordenadora da EA: "A questão do dia do Meio Ambiente, onde nós fizemos o plantio de mudas. Tivemos a passeata no campus, fizemos realmente um barulho grande no campus". Para Vaz (1995), uma simples passeata é um componente de mobilização em prol de uma causa, uma forma de conscientização socioambiental.

O projeto social do CF trabalha com a oferta de cursos profissionalizantes gratuitos, gerando possibilidades de oportunidades para o mercado de trabalho, sendo que seus professores são ou foram alunos da Universidade. $\mathrm{Na}$ fala do vice-reitor, é percebida a importância da capacitação no CF: "está capacitando essas pessoas a conseguirem uma profissão e também está modificando o perfil dessas pessoas, que passam do trabalho informal para o trabalho formal".

Quanto ao Marketing Social do projeto, o projeto, por si, tem uma boa imagem, como disse uma professora: "uma das coisas que eu acho mais interessantes no $\mathrm{CF}$, não só eu, mas todos os outros instrutores também, é que nós não fazemos divulgação. Não é? A divulgação que nós fazemos ela é bem pequena. Ainda assim, as nossas datas de inscrição elas estão lotadas". O Marketing Social cria um comportamento de modo que as pessoas se engajem em projetos de Responsabilidade Social (McKENZIE-MOHR, 2000).

No entendimento da Coordenadora do PJV, "O voluntário ele fica totalmente diferente quando ele sai. Ele fica mais humano, ele fica com mais traquejo social, ele fica vendo o mundo com os outros olhos [...] eles começam a se humanizar, [...] muito mais tolerantes, muito mais perceptivos, muito mais gente". Ficou claro que o projeto funciona em favor dos seus executores em termos de responsabilidade social, já que leva as pessoas a se tornarem mais humanas e altruístas.

Com relação ao Marketing Social, "a gente vê que falta um pouquinho de mais incentivo para gente, sabe assim, porque a universidade ela tem programa de TV, ela tem jornais informativos, ela tem um site" (EST_PJV1). O projeto de responsabilidade social do Jovem Voluntário deve ser mais difundido não só no âmbito da Universidade, em virtude da sua grande relevância. Isso é possível por meio do Marketing Social, que funciona no plano institucional, objetivando minorar problemas sociais e ou carências da sociedade, como, por exemplo, questões de higiene e saúde pública (VAZ, 1995; MATTOZO; CAMARGO, 2005). 
Da relação do PESDA com a Responsabilidade Social emergiram as seguintes categorias: Educação e Cidadania, Capacitação, Criatividade, Saúde e Conscientização Ambiental. No tocante à educação e à cidadania, a coordenadora do projeto relatou que existem "adultos que são analfabetos e que aprendem minimamente com o projeto, e que, já deram depoimentos eu tenho isso gravado de se orgulhar de que não ter mais que botar o dedo lá na clínica, poder assinar o nome, entendeu?”(COORDENADORA_PESDA).

O projeto promove a liberdade individual, uma vez que seu produto social, por via de atividades didático-pedagógicas, possibilita essa expansão da liberdade da pessoa que encontra a chance de ter uma escola dentro de um hospital, em um espaço totalmente inapropriado para tal, configurando assim uma melhoria da qualidade de vida, por intermédio desse rearranjo social (SEN, 1999b). É uma capacitação de mão dupla. Uma aluna voluntária considera o projeto "um treinamento completo, dizendo tudo que a gente vai ter que fazer, mostrando, apresentando a nós a clínica. Apresentando a nós os pacientes, como ocorre o processo de hemodiálise, quais são os tipos de tratamento para o insuficiente renal crônico...”.

A criatividade e a inovação estão presentes por meio de atividades lúdicas, que os bolsistas e voluntários do projeto executam em um ambiente hospitalar "deixam a gente bem livre para a gente escolher a forma que a gente quer passar as atividades [...] $\mathrm{Na}$ alfabetização, quanto mais você inovar, mais fácil ela é do paciente aprender...” (BOLSISTA_PESDA).

O NMEDI é sustentado pela Fundação Educacional e funciona como espaço de prática acadêmica dos cursos de Terapia Ocupacional, Fonodiaulogia, Fisioterapia, Psicologia, Nutrição e Medicina. Além disso, conta com um Ambulatório, um Laboratório de Análises Clínicas, um Centro de Diagnóstico, uma Farmácia e uma Academia. É um estabelecimento de assistência em saúde de nível de atenção secundária, atendendo a pacientes do SUS, particulares e convênios. Sendo assim, atende a funcionários da Universidade conveniados e situações de interesse acadêmico.

Com suporte nos dados colhidos com os alunos, responsáveis técnicos, professores, coordenadores, administrador e diretor do NMEDI, a relação do projeto com a Responsabilidade Social acontece via atendimento humanizado, cuidados com a saúde física e mental, suporte à vida na comunidade e capacitação acadêmica, bem como pela conscientização ambiental. O administrador do NMEDI, quanto ao tratamento humanizado, disse: "a gente tem que se colocar mais no local do outro, no lugar do próximo, saber a começar a aparar essas arestas e tentar ser menos exclusivo, [...] não só trazer isso para a saúde, que é um ambiente, que precisa ser mais humanizado...”. 
Ainda mais importante do que o simples acesso aos serviços de saúde; é essencial melhorar a saúde dos seres humanos. Questões como segurança alimentar, medidas educativas na prevenção de doenças e vacinação constituem maneiras de atingir aquele objetivo (VAZ, 1995). No tocante à saúde, a coordenadora da Fisioterapia afirmou que "os projetos sociais eu acho que são ousados todos eles. É o trabalhar com o idoso, é o trabalhar com a reabilitação cardíaca”. Esses também são trabalhos exercidos pelo NMEDI.

Quanto ao atendimento humanizado como ferramenta de Marketing Social, para o NMEDI, é associado teoricamente aos ensinamentos do Centro Britânico de Marketing Social que, segundo French e Blair-Stevens (2006), utiliza os fundamentos do marketing comercial para atingir comportamentos apropriados ao fomento do bem social. Nesse sentido, está relacionando com as teorias éticas de responsabilidade social, inseridas na linha do bem comum (MELÉ, 2002).

No tocante a formação do aluno para a cidadania, um professor do curso de Odontologia asseverou: "nós professores e a universidade têm a obrigação nesse intuito também de cuidar dessa sociedade. E quanto a isso, eu preciso entregar um profissional, sobretudo, muito bem preparado, entretanto, sobretudo ético...”. A cidadania e o acesso à saúde odontológica gratuita são pontos-chave para a comunidade de entorno e demais comunidades carentes daqueles serviços.

A preocupação com o meio ambiente vai além das normas de biossegurança próprias de clínicas-escola de saúde, como afirmou o professor: “o aluno não precisa só ter esse cuidado aqui, mas é muito importante que ele leve esse cuidado, quando ele passar dos muros da universidade lá para fora...".

O EJ funciona desde 2001 como campo de prática para os estudantes de Direito, monitorados por professores do curso em estágios curriculares. O EJ tem um convênio com a Defensoria Pública estadual e atende pessoas hipossuficientes, ou seja, pessoas pobres na forma da lei, ou seja, como núcleo de petição inicial o EJ atende gratuitamente aqueles que não têm condição de pagar advogado, mas que precisam de orientação, e em certos casos encaminhamentos no âmbito do Judiciário.

A educação e a cidadania constituem uma maneira da Fundação Educacional fazer o marketing social, como disse a assistente social em relação ao projeto do Escritório Jurídico: “o acesso à concretização da cidadania, acontece por meio da informação. Então, a partir do momento que a gente presta informações, que a gente esclarece sobre direitos, nós estamos proporcionando a concretização de certa cidadania”. Isso leva a uma ética superior que foge a 
uma lógica economicista de formar alunos somente para o mercado de trabalho, trazendo à baila a importância também de um profissional humanizado e sensível a questões socioambientais.

O PCATU é um projeto da Fundação Educacional de Responsabilidade Social atuante desde 2001, que envolve voluntariamente alunos do curso de Direito e professores dos cursos de graduação da Universidade. O programa leva noções de cidadania às comunidades carentes, bem como orientação jurídica. É considerado um projeto de ensino e de extensão que vale como atividades complementares na matriz curricular do aluno, que se realizam na forma de grupos específicos sobre uma temática mediante a supervisão e ensino de um professor. "O Cidadania Atuante ele tem esses dois vieses, ele é, ele tem um viés que é eminentemente um projeto de ensino, e é um projeto de ensino que leva também a um projeto de extensão" (COORDENADORA_PCATU).

No entendimento de Boff (2012), a cidadania só se realiza quando existem acesso e conscientização sobre direitos humanos essenciais, como serviços de saúde, educação formal em todos os níveis, saneamento básico, igualdade de gênero e inexistência de discriminações de qualquer tipo. A orientação jurídica promove a liberdade individual (SEN, 2000) das pessoas, uma vez que o trabalho de Responsabilidade Social do PCATU leva à população carente nas comunidades o conhecimento de seus direitos e obrigações, que muitas vezes são ignorados ou mal interpretados em decorrência da desinformação. Sendo assim, este projeto também promove o Marketing Social através da Responsabilidade Social.

\section{CONCLUSÃO}

Uma característica comum aos projetos de Responsabilidade Social da Universidade é que eles são mantidos pela Fundação Educacional; ajudam na formação educacional do aluno, além de formar cidadãos. Esses projetos concedem acesso gratuito pelas comunidades, promovendo a capacitação profissional, orientação e qualificação para o mercado, bem como cuidados com a saúde. $\mathrm{O}$ voluntariado é uma característica evidente neles, além de promover a educação e a conscientização socioambiental.

Esses projetos sociais fomentam a inclusão social e a promoção do bem comum na luta pelos direitos humanos, por intermédio de valores, como solidariedade, ética socioambiental e altruísmo, além de envolverem a família e um atendimento humanizado. São projetos de Responsabilidade Social pautados pela prática do Marketing Social. 
A Fundação Educacional também disponibiliza a sociedade serviços essenciais, por meio dos alunos de graduação e profissionais da Universidade nas diversas áreas do saberDireito, Medicina, Odontologia, Psicologia, Serviço Social, Enfermagem, Fisioterapia, Terapia Ocupacional, Fonoaudiologia, Educação Física etc. Esse trabalho da Fundação Educacional é multiplicado pelos alunos e profissionais envolvidos, entretanto, principalmente, pelos beneficiados pelos projetos sociais. Assim, essa é uma contribuição de Responsabilidade Social relevante inserida no contexto do Marketing Social, sendo gerida por uma universidade privada suportada por uma Fundação.

Ao incorporar várias subunidades de análises em um caso único, a pesquisa ganhou com o detalhamento de cada projeto, pois foi necessário retornar a unidade de análise maior, a Fundação Educacional. Sendo, que mesmo obtendo mais profundidade sobre o tema do Marketing Social, os resultados não são generalizáveis, já que, são aplicados tão-somente a situação caso. Como sugestão de pesquisas futuras seria interessante fazer um trabalho deste mesmo teor em organizações estritamente lucrativas para analisar como se dá o relacionamento entre as ações de Marketing Social oriundas de estratégias de Responsabilidade Social Corporativa.

A Fundação Educacional promove novas formas de trabalho para inclusão social na comunidade local, bem como incentiva a cultura regional, fomentando muito mais do que um apoio meramente econômico, mas também oferecendo ganhos sociais por via do Marketing Social. Os projetos de Responsabilidade Social fomentam o envolvimento de docentes, discentes, funcionários e comunidade do entorno da Universidade, além de parcerias e alianças institucionais. Os principais elementos que influenciam essa prática estão relacionados com a humanização dos futuros profissionais, formação da cidadania nas comunidades atingidas, na educação e na capacitação, servindo também como laboratório de práticas universitárias para os alunos.

\section{AGRADECIMENTOS}

Gostaria de agradecer $a$ CAPES - Coordenação de Aperfeiçoamento de Pessoal de Nível Superior e a Fundação Cearense de Apoio ao Desenvolvimento Científico e Tecnológico- FUNCAP pelo apoio a esta pesquisa. 


\section{REFERÊNCIAS}

ANDRADE, M. D. de; COSTA, R. G. Ações conjuntas pela promoção da inclusão: atividade física e educação como práticas para o desenvolvimento da responsabilidade social na Universidade de Fortaleza In: POMPEU, R. M.; MARQUES, C. S. da E (Orgs.).

Responsabilidade social das universidades. Florianópolis: Conceito Editorial, 2013. 352 p.

ASHLEY, P. A. et al. (Org.). Ética e Responsabilidade Social nos Negócios. São Paulo: Saraiva, 2002.

AUSTIN, J.; STEVENSON, H.; WEI-SKILLERN, J. Social and commercial entrepreneurship: same, different, or both? Entrepreneruship Theory and Practice, v. 30, p. $1-22,2006$.

BARDIN, L. Análise de conteúdo. Lisboa: Edições 70, 1977.

BELZ; F. M.; SCHMIDT-RIEDIGER, B. Marketing strategies in the age of sustainable development: evidence from the food industry. Business Strategy and the Environment, v. 19 , n. 6, p. 401-41, 2010.

BOFF, L. Sustentabilidade o que é e o que não é. Petrópolis: Vozes, 2012.

BRASIL, M. V. de O. Empreendedorismo sustentável em projetos sociais de uma fundação educacional. 2014. 313 f. Tese (Doutorado em Administração) - Universidade de Fortaleza (UNIFOR), Fortaleza, 2014.

BUARQUE, C. Qualidade de vida: a modernização da utopia. Lua Nova, n. 31, São Paulo, dez. 1993.

BURSZTYN, M.; BURSZTYN, M. A. Fundamentos de política e gestão ambiental: os caminhos do desenvolvimento sustentável. Rio de Janeiro: Garamond, 2012. 612 p.

CAMARGO, A.; CAPOBIANCO, J. P. R.; OLIVEIRA, J. A. P. de. (Orgs.). Meio ambiente Brasil: avanços e obstáculos pós-Rio-92. 2. ed. rev. São Paulo: Estação Liberdade: Instituto Socioambiental: Rio de Janeiro: Fundação Getúlio Vargas, 2004. 473 p.

CEARÁ (Estado). Cenário atual do semiárido cearense. Conselho de Altos Estudos e Assuntos Estratégicos, Assembléia Legislativa do Estado do Ceará. Eudoro Walter de Santana (Coord.). Fortaleza: INESP, 2011. 482 p.

COLOMBO, S. S. et al. Marketing educacional em ação: estratégias e ferramentas. Porto Alegre: Artmed/Bookman, 2005.

CORNELISSEN, G. et al. Whatever people say I am, that's what I am: Social labeling as a social marketing tool. International Journal of Research in Marketing, n. 24, p. 278-288, 2007.

CRUZ, E. Q. A UNIFOR e a Comunidade Carente. Fortaleza: Universidade de Fortaleza, 1998. $50 \mathrm{p}$. 
FONSECA, I. F. da; BURSZTYN, M. Mercadores de moralidade: a retórica ambientalista e a prática do desenvolvimento sustentável. Ambiente \& Sociedade, Campinas, v. X, n. 2, p. 171-188, jul./dez. 2007.

FRENCH, J.; BLAIR-STEVENS, C. From snake oil salesman to trusted policy advisors: the development of a strategic approach to the application of social marketing in England. Social Marketing Quarterly, v. 12, n. 3, p. 29-40, 2006.

GUATTARI, F. As três ecologias. 14. ed. Campinas: Papirus, 1990.

IPECE- INSTITUTO DE PESQUISA E ESTRATÉGIA ECONÔMICA DO CEARÁ. A caracterização da extrema pobreza no estado do Ceará: baseado nos dados do censo 2010 . Informe no 09, IPECE, jun., 2011.

JANSSON, J.; MARELL, A. Green consumer behavior: determinants of curtailment and ecoinnovation adoption. Journal of Consumer Marketing, v. 27, n. 4, p. 358-370, 2010.

KOTLER, P.; ROBERTO, E. Marketing Social: estratégias para alterar o comportamento público. Rio de Janeiro: Campus, 1992.

KOTLER, P.; ZALTMAN, Gerald. Social Marketing: an approach to planned social change. Journal of Marketing, v. 35, p. 3-12, jun. 1971.

LEVITT, T. A imaginação de marketing. Trad. Auriphebo Berrance Simões e Nivaldo Montingelli. 2. ed. São Paulo: Atlas, 1990.

MATHEW, V. Sustainable entrepreneurship in small-scale business: application, concepts and cases. The ICFAI University Journal of Entrepreneurship Development, v. 6, n. 1, p. 41-61, 2009.

MATTOZO, V.; CAMARGO, C. C. de B. Energia ambiente \& mídia: qual é a questão? Florianópolis: Ed. da UFSC, 2005. 183 p.

McKENZIE-MOHR, D. Promoting Sustainable Behavior: An Introductory to CommunityBased Social Marketing. Journal of Social Issues, v. 56, n. 3, p. 543-554, 2000.

MELÉ, D. Not only stakeholders interests. The firm oriented toward the common good. Notre Dame: Univesity of Notre Dame, 2002.

NIDUMOLU, R.; PRAHALAD, C. K.; RANGASWAMI, M. R. Why sustainability is now the key driver of innovation. Havard Business Review, set. 2009. Disponível em: $<$ http://www.hbr.org $>$. Acesso em: 21 jun. 2012.

PEATTIE, K. K.; PEATTIE, S. Social marketing: A pathway to consumption reduction? Journal of Business Research, n. 62, p. 260-268, 2009.

POMPEU, R. M.; MARQUES, C. S. da E. (Orgs.). Responsabilidade social das universidades. Florianópolis: Conceito Editorial, 2013. 352 p. 
PRINGLE, H.; THOMPSON, M. Marketing Social: marketing para causas sociais e a construção das marcas. Trad. Maria Lúcia G. L. Rosa. São Paulo: Makron Books, 2000.

SCHALTEGGER, S.; WAGNER, M. Sustainable entrepreneurship and sustainability innovation: categories and interactions. Business Strategy and the Environment, n. 20, v. 4, p. 222-237, 2011.

SCHRADER, U.; THOGERSEN, J. Putting Sustainable Consumption into Practice. J. Consum. Policy, n. 34, p. 3-8, 2011.

SEN, A. K. The perspective of freedom. New York: First Anchor Books, 1999a. . Sobre ética e economia. Trad. Laura Teixeira Motta. São Paulo: Companhia das Letras, 1999b.

Desenvolvimento como liberdade. Trad. Laura Teixeira Motta. São Paulo:

Companhia das Letras, 2000.

SHRIBERG, M. Towards sustainable management: the University of Michigan Housing Division's approach. Journal of Cleaner Production, n. 10, p. 41-45, 2002.

SILVERMAN, D. Interpretação de dados qualitativos: métodos para análise de entrevistas, textos e interações. 3. ed. Porto Alegre: Bookman, 2009.

TACHIZAWA, T. Gestão ambiental e responsabilidade social corporativa: estratégias de negócios focadas na realidade brasileira. 5. ed. rev. e amp. São Paulo: Atlas, 2008.

VAZ, G. N. Marketing Institucional: o mercado de idéias e imagens. São Paulo: Pioneira, 1995.

WERBACH, A. Strategy for sustainability: a business manifesto. United States of America: Harvard Business Press, 2009, 229 p.

WEST, R. E. What is shared? A framework for understanding shared innovation within communities. Education Tech Research Dev., v. 57, p. 315-332, 2009.

YIN, R. K. Estudo de caso: planejamento e métodos. 3. ed. Porto Alegre: Bookman, 2005, $212 \mathrm{p}$. 